\title{
An orchid colonization credit in restored calcareous grasslands
}

${ }^{a}$ University of Leuven, Biology Department, Plant Ecology, Kasteelpark Arenberg 31, B3001 Leuven, Belgium.

${ }^{\mathrm{b}}$ University of Leuven, Division of Forest, Nature and Landscape, Celestijnenlaan 200 E, B3001 Leuven, Belgium.

* Contact information: 


\section{Abstract}

Habitat restoration comprises the recreation of suitable environmental conditions with the intention of recolonization by certain target species. In previously abandoned calcareous grasslands, however, many characteristic plant species have been reported missing, even decades after the reinstatement of the traditional mowing or grazing management. Such grasslands are said to exhibit a colonization credit. This may be particularly true for orchid species, which often rely on highly specialized pollination strategies and mycorrhizal associations for completion of their life-cycle. In this study, we investigated whether restored calcareous grasslands exhibited an orchid colonization credit, whether this credit was associated with the degree of grassland fragmentation, and with particular species' life history traits. Applying the Beals index as a quantitative method to identify suitable habitats, several orchid species were indeed found missing from grasslands deemed suitable. There was no relation, however, between the extent of the colonization credit and the spatial isolation or size of the grasslands. From all life history traits examined, only a high degree of pollinator specialization could be related to delayed colonization. This may suggest that restoring the pollinator community is an important bottleneck in calcareous grassland restoration.

44 Keywords: Beals index, habitat suitability, colonization delay, habit fragmentation, life 45 history traits, specialized pollination, grassland management 


\section{Introduction}

47

Temperate grasslands are one of the world's most species rich plant-communities at a small scale $\left(<10 \mathrm{~m}^{2}\right)$. Especially calcareous grasslands are known to be highly diverse, with up to 60 plant species $\cdot \mathrm{m}^{-2}$ (Kull \& Zobel, 1991; Eriksson \& Eriksson, 1997). Next to the high plant diversity there is an even greater diversity of arthropod species, which makes these nutrient-poor grasslands regional biodiversity hotspots (WallisDeVries, Poschlod \& Willems, 2002; Cremene et al., 2005). Historically, calcareous grasslands were limited to extreme environmental conditions on steep calcareous mountain slopes. Early human activities such as deforestation and increased sheep flock migrations (transhumance) increased their area and maintained these grasslands on calcareous hills all over Western Europe (Poschlod \& WallisDeVries, 2002). By the end of the $19^{\text {th }}$ century, free sheep grazing declined steeply due to urbanization, the collapse of the local wool market and intensification of agriculture through fertilizers (Poschlod \& WallisDeVries, 2002). Through natural succession, these unattended grasslands slowly started to transform. First species to disappear were annual and shade-intolerant species due to dominance of some grasses (mostly Brachypodium pinnatum or Bromus erectus) (Bobbink \& Willems, 1987). As the herbaceous layer grew higher and denser, seed germination and seedling establishment of typical grassland species declined (Delescaille et al., 2005; Jacquemyn et al., 2011), and grasslands species were replaced by shrub and tree species. In many parts of north-western Europe, efforts to restore the overgrown grasslands only started in the 1970s (Delescaille et al., 2005).

Restoration success largely depends on two factors, (i) the recreation and maintenance of suitable environmental conditions, and (ii) the recolonization of target species (Perrow \& Davy, 2002, Piqueray \& Mahy, 2010). Restored grasslands that are deemed suitable with respect to habitat quality, and that have not yet been fully colonized are said to exhibit a 
'colonization credit' (Cristofoli et al., 2010). We define colonization credit as the number of species yet to colonize a grassland, following the restoration of habitat quality. In quantifying the colonization credit, it is crucial to be able to determine the habitat suitability for target species. Including direct measures of habitat suitability, such as for example soil characteristics, is not a trivial task as there are many candidate variables, and there is no objective procedure to decide which ones are the most relevant (Münzbergová \& Herben, 2004). To meet this problem, measures of habitat suitability that are based on the species composition of all present species in a habitat have been proposed. This approach can be based on a hypervolume approach based on Ellenberg indicator values (Butaye et al., 2002), or on the Beals Index (BI) (Beals, 1984; Munzbergova \& Herben, 2004). The application of the BI is based on the general observation that occurrences of species are correlated (Munzbergova \& Herben, 2004).

Before a habitat that is deemed qualitatively suitable is successfully colonized, different sequential successes are necessary. First, dispersal of propagules is required, followed by establishment of individuals, and their survival and growth to reproductive individuals (Jackson \& Sax, 2010). If any of these steps is delayed or obstructed, it causes a delay in the colonization of a habitat, resulting in colonization credit (Jackson \& Sax, 2010). Colonization delays happen frequently and have been demonstrated for non-native species invasions (Kinlan \& Hastings, 2005), natural, climate-driven migrations (Menendez et al., 2006; Willis et al., 2009), and for the colonization of newly created habitats (Jacquemyn, Butaye \& Hermy, 2003, Cristofoli et al., 2010). Habitat fragmentation can be expected to be an important driver of delayed colonization for two reasons. First, habitat area may hamper successful colonization because small grasslands can only harbour small populations which are more susceptible to local extinction through environmental and demographic stochasticities, natural catastrophes and reduced genetic diversity (Shaffer, 1981). Second, 
spatial isolation of habitats is expected to negatively affect both the survival of small populations through impeding a rescue effect (Brown \& Kodrick-Brown, 1977) and the (re-) colonization of habitat (Hanski, 1998).

Species richness has been widely used as a biological indicator of restoration success in calcareous grasslands (e.g. Lindborg \& Eriksson, 2004), even though it is a rather rough indicator (Kiehl, Thormann \& Pfadenhauer, 2006). Other indicators can be useful to evaluate the efficiency of restoration practices (Samu, Csontos \& Szinetár, 2008). Orchid species are among the most recognizable members of the plant kingdom. Because they are habitat specialists and are largely dependent on, often specialized, biotic interactions with insect pollinators and mycorrhizal fungi (Waterman \& Bidartondo, 2008; Swarts \& Dixon, 2009), they can be considered as good indicators of ecosystem health and ecosystem integrity (Swarts \& Dixon, 2009). Even among orchid species, however, important trait differences occur, e.g. with respect to plant height, longevity, pollinator and mycorrhizal specialization, and nectar production. Because plant traits are important mediators of a species' responses to habitat deterioration, fragmentation and restoration (Jacquemyn, Brys \& Willems, 2005; Adriaens, Honnay \& Hermy,, 2007; Swarts \& Dixon, 2009) it can be expected that there is some variability in the colonization delay among different orchid species.

Here, we investigated whether once deteriorated calcareous grasslands exhibit an orchid colonization credit, more than three decades after the reinstatement of the traditional management. Because, as in many restoration studies, a clear reference habitat is lacking, and restoration sites vary in habitat quality, we applied the BI as a quantitative method to detect suitable grasslands. More specifically this paper aims to:

1. Determine the reliability of the BI for estimating habitat suitability by comparing it with abiotic habitat quality measures;

2. Use the BI to evaluate the presence of an orchid colonization credit by identifying 
suitable but unoccupied grasslands;

3. Evaluate whether the colonization credit is associated with small habitat area and low habitat connectivity;

4. Identify orchid life history traits that mediate delayed colonization.

(1)

\section{STUDY AREA AND SPECIES}

The study area roughly coincides with the valley of the river Viroin in the southwestern part of the Calestienne region, Southern Belgium (Figure 1; Adriaens, Honnay \& Hermy, 2007). It covers approximately $80 \mathrm{~km}^{2}$. The soil has been formed in a southwest to northeast oriented geological belt of Devonian limestone hills. The calcareous grasslands can be found on stony outcrops, on altitudes between 150 and $250 \mathrm{~m}$. The mean annual temperature is $9.8{ }^{\circ} \mathrm{C}$ and the area receives a mean annual precipitation of $780 \mathrm{~mm}$ (Royal Meteorological Institute Belgium). The studied calcareous grasslands were once part of a larger grazing system with migrating sheep flocks. By the end of the $18^{\text {th }}$ century free grazing practices diminished and are suspected to have stopped completely by 1950 . It was not until the 1970s that the first attempts were made to manage and restore the habitat quality of the remnant grassland. Until the 1990s, grasslands were managed dominantly by mowing and after that date grazing became most important (Adriaens, 2008). In an earlier study of these grasslands, Adriaens et al. (2006), have been reconstructing the historical area of the individual grassland fragments since 1775 , and they were not able to demonstrate a species extinction debt. Here, we adopt a different view on these grasslands, by recognizing that even the grasslands still present today have gone through a period of succession and shrub 
encroachment, and that they regained habitat quality only during the last 30 years, through the reinstatement of the mowing and grazing regime.

The presence of herbaceous plant species was surveyed in 64 grasslands. Surveys were conducted in spring and late summer 2004, by walking parallel transects through the entire grassland. Species found were then added to a pre-existing list of $4151 \mathrm{~m}^{2}$ vegetation relevés, recorded in 2003 (Butaye et al., 2005). The number of established relevés was in proportion to the grassland area, ranging between 2 and 30 per grassland.

Only the 120 habitat specialist species that belonged to the typical Festuco-Brometea, Sedo-Scleranthea and Trifolio-Geranietea vegetation types were listed (Butaye et al., 2005). Of these species, only 90 species that occurred in at least five grasslands were retained for further analysis. Of the 20 orchid species occurring in the study area, nine species met these criteria: Epipactis atrorubens, Gymnadenia conopsea, Himantoglossum hircinum, Listera ovata, Ophrys fuciflora, Ophrys insectifera, Orchis anthropophora, Orchis mascula and Platanthera chlorantha (nomenclature according to Lambinon et al., 2004). We classified the species according to nectar production (yes or no), average plant height at inflorescence (short or tall ( $<$ or $\geq 30 \mathrm{~cm}$ respectively)), growth habit (rhizomatous or tuberous), lifespan (short- or long-lived ( $\leq$ or $>3$ years respectively)), pollination (specialized or general $(\leq$ or $>10$ pollinator species respectively)) and self-compatibility (yes or no) (Table I). Plant traits were retrieved from literature (Van der Cingel, 1995, Kull \& Hutchings, 2006, Schatz, 2006).

\section{ENVIRONMENTAL VARIABLES, GRASSLAND SUITABILITY AND CONNECTIVITY}

In each relevé, we measured the following environmental variables: percentage cover of bryophytes, rock and bare ground, average vegetation height $(\mathrm{cm})$, soil depth $(\mathrm{cm})$ and slope (\%). Total standing biomass was estimated by multiplying vegetation cover with mean vegetation height. All environmental variables were averaged across all the vegetation relevés 
established in a grassland.

Using plant coexistence matrices, the BI was calculated according to the following formula (Beals, 1984; Munzbergova \& Herben, 2004):

$$
\mathrm{p}_{\mathrm{ij}}=\mathrm{S}_{\mathrm{i}}-1 \cdot \sum_{\mathrm{k}} \cdot \mathrm{N}_{\mathrm{jk}} \cdot \mathrm{N}_{\mathrm{k}}^{-1}
$$

where $p_{i j}$ is the probability of finding species $j$ at site $i, S_{i}$ is the species richness of site $i$ (minus 1 if species $\mathrm{j}$ is present), $\mathrm{N}_{\mathrm{jk}}$ is the number of joint occurrences of species $\mathrm{j}$ and $\mathrm{k}$ in the predictor sites and $\mathrm{N}_{\mathrm{k}}$ is the number of occurrences of species $\mathrm{k}$ in the predictor sites. For each orchid species, unoccupied grasslands were defined as suitable if they had a BI higher than the $5^{\text {th }}$ percentile of the cumulative frequency distribution of the BI of occupied grasslands (Munzbergova \& Herben, 2004).

For each grassland $\mathrm{i}$ the connectivity $\left(\mathrm{C}_{\mathrm{i}}\right)$ was calculated according to Moilanen and Nieminen (2002) using the formula:

$$
C_{i}=\sum\left(A_{i} \cdot A_{j}\right) \cdot d_{i j}^{-1}
$$

Where $A_{i}$ is the area of grassland $i, A_{j}$ is the area grassland $j$ and $d_{i j}$ is the Euclidean distance between grassland $\mathrm{i}$ and $\mathrm{j}$

\section{DATA ANALYSES}

For each orchid species, the reliability of the BI estimations of habitat suitability was verified by comparing the BI between occupied and unoccupied grasslands using a MannWhitney U test. Next, we restricted our analyses to unoccupied grasslands and tested whether the measured environmental variables were related to the suitability of a grassland (1/0) as estimated by the BI. To avoid the problem of intercorrelation, a dimension reduction was performed on the environmental variables, using a Principal Component Analysis (PCA) with varimax rotation. Significance between Principal Components and environmental variables 
195

196

197

198

199

200

201

202

203

204

205

206

207

208

209

210

211

212

213

214

215

were determined by calculating Pearson correlation coefficients between principal component scores and environmental variables. We then used a backward stepwise binary logistic regression to relate the Principal Components to grassland suitability. To determine significance, Wald statistics were calculated.

To evaluate the extent of the orchid colonization credit in our study area, observed grassland occupancy was compared with the number of suitable grasslands (as determined by BI), and the average orchid colonization credit across all grasslands was determined. In order to evaluate the effects of grassland fragmentation on the colonization credit, we performed Spearman rank correlations between the orchid colonization credit of a grassland (i.e. number of orchid species missing) and grassland connectivity, and between orchid colonization credit and grassland area. Area and connectivity were not correlated $(\mathrm{p}>0.1)$. To identify traits that may mediate the delayed colonization of orchids, orchid traits were linked to their incidence in suitable grasslands, using a Mann-Whitney U test. All analyses were carried out using SPSS 17.0.

\section{Results}

unoccupied grasslands $(\mathrm{p}<0.05)$. More importantly, occupied grasslands generally had a high BI, whereas unoccupied grasslands could have both high and low BI value (Figure 2).

The PCA analysis on the environmental variables yielded three Principal Components (PC) with an eigenvalue higher than 1 . Together they represented $74 \%$ of the total variance (Table I). All environmental variables correlated very significantly $(\mathrm{p}<0.001)$ to one of the three PC. Biomass and vegetation height were positively correlated with PC 1. PC 2 
correlated positively with slope and percentage of rock, and negative with soil depth. PC 3 was negatively correlated with percentage cover of bare ground, and positively with percentage cover of bryophytes. Unsuitable grasslands were markedly different from unoccupied suitable grasslands with respect to PC 2 (Table II). However, optimal environmental conditions were not identical for all orchid species. Depending on the species considered, either high or low values of PC 2 were deemed appropriate.

Orchid species occupied 20-70\% of all suitable grasslands (Figure 3), and on average, half of all suitable grasslands were occupied. The orchid colonization credit of a grassland was independent of both its area and its isolation (both $\mathrm{p}>0.1$; Spearman rank correlations) (Figure 4). Three orchid traits, lifespan, self-compatibility and average height, could not be related to the incidence of orchids in suitable grasslands as there was insufficient variation among the orchid species considered. Nectar production did not significantly influence the percentage of suitable habitats occupied $(Z=0.26 ; p=0.90)$, neither did habitat preference $(Z$ $=0.98 ; p=0.33)$ or growth habit $(Z=0.44 ; p=0.66)$. Orchids with generalized pollination occupied significantly more suitable grasslands than orchids with specialized pollination $(\mathrm{Z}=$ 2.46; $\mathrm{p}=0.01$ ). Orchids with specialized pollination were present in approximately $40 \%$ of the suitable habitats, while orchids with a high number of potential pollinators could be found in approximately $60 \%$ of the suitable habitats.

\section{ARE GRASSLAND SUITABILITY ESTIMATIONS RELIABLE?}

The calculated BI of the grasslands occupied by orchid species is generally high, confirming their suitability, while the BI of unoccupied grasslands could be both high or low 
245 (Figure 2), suggesting that some of these grasslands are suitable, while others are unsuitable.

246 These results at least indicate that the BI estimations are able to differentiate between habitats,

247 and that they can provide a predictive value of habitat suitability (Münzbergová \& Herben,

248 2004). Although the BI has been recommended as an indicator of habitat suitability (Ewald,

249 2002; Münzbergová \& Herben, 2004; Pärtel, Szava-Kovats \& Zobel, 2011) it has never been

250 directly related to environmental conditions. We found a significant difference between

251 suitable vs. unsuitable unoccupied grasslands with respect to the environmental variables

252 (PCs) measured for six orchid species. Three other species showed no relation at all $(\underline{H}$.

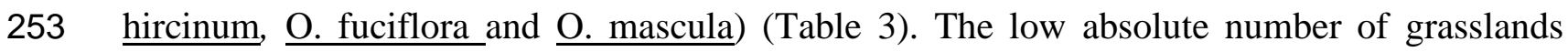

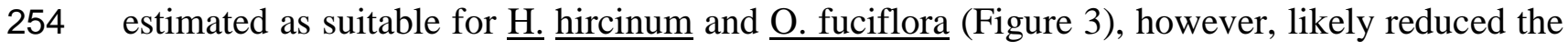

255 power of our analysis. Additionally, other unmeasured abiotic variables such as soil nutrient

256 conditions may affect habitat suitability (Jacquemyn, Brys \& Hermy, 2003; Pärtel et al.,

257 2007). Our results therefore confirm the high discriminatory power of the BI.

\section{EVIDENCE OF AN ORCHID COLONIZATION CREDIT?}

Piqueray et al. (2011a) have recently demonstrated that many typical grassland species were unable to colonize calcareous grasslands, up to 15 years after forests clearance. Our results show that even three decades after the restoration of degraded calcareous grasslands, orchid species are still only present in approximately half of the habitat grasslands that are deemed suitable. If the grasslands used as a reference for habitat suitability would have an extinction debt, our results would overestimate the number of suitable habitats (Piqueray et al., 2011b). However, this is not the case (Adriaens, Honnay \& Hermy, 2006), and our data therefore suggest that suitable environmental conditions have been restored. 
for 4.2 orchid species, from which 2 have not colonized yet.

271

272

273

274

275

276

277

278

279

280

\section{IS THE COLONIZATION CREDIT ASSOCIATED WITH HABITAT FRAGMENTATION?}

If the observed colonization credit was caused by high extinction rates in particularly small grassland areas, we would have expected to find a higher colonization credit in smaller grasslands, which was not the case. If isolation was responsible for the colonization credit, we would have expected to find a higher colonization credit in more isolated grasslands. Again no such relation was found.

The absence of a relation between orchid occurrence and grassland isolation may be due to the relatively good dispersal capacities of orchid species, making spatial isolation not the primary determinant of orchid occurrence in grasslands that are assessed suitable (Arditti \& Ghani, 2000). First, orchids produce excessive amounts of small dust-like seeds. Only a small part of such a seed contains the embryo while the remainder is filled with air. As a result, orchid seeds can remain airborne for long periods and can disperse relatively far (Arditti \& Ghani, 2000). Second, the use of migrating sheep flocks between some but not all grasslands could easily eliminate the effects of spatial isolation between those grasslands. Sheep are excellent seed dispersers, both through exo- and endo-zoochory (Adriaens, Honnay \& Hermy, 2007; Kuiters \& Huiskes, 2010). Once established, a regular exchange of seeds between founder populations is also necessary for the successful establishment of viable populations. Gene flow through seeds can counter the effect of small effective population size and genetic drift through the input of new alleles (Young, Boyle \& Brown, 1996; Jacquemyn et al., 2009). To conclude, there is no evidence that habitat fragmentation is the primary cause of the observed orchid colonization credit in calcareous grasslands. The question therefore remains which factors hamper the colonization of grasslands that are assessed suitable based on the $\mathrm{BI}$. 
296

297

298

299

300

301

302

303

304

305

306

307

308

309

310

311

312

313

314

315

\section{DO LIFE HISTORY TRAITS MEDIATE THE DELAYED COLONIZATION OF ORCHIDS?}

Neither nectar production nor growth habit significantly affected the percentage of suitable habitats occupied. Orchids with specialized pollination, however, occupied a significantly lower percentage of suitable grasslands compared to orchids with many potential pollinators, indicating that there is a stronger colonization delay for orchids with specialized pollination. Orchid rarity has often been linked to unique pollinator requirements (Swarts \& Dixon, 2009, Phillips et al., 2011a). Seed set of specialised orchids can be limited by the behaviour and ecology of only a single pollinator species, thereby affecting population growth and colonisation ability of a species (Phillips et al., 2011a, b). Numerous factors such as the lack of specific habitat requirement (e.g. nesting sites), the absolute and relative abundance of flowering species (e.g. Rasheed \& Harder, 1997), competition with different pollinator species (Bowers, 1986), and even weather conditions are known to influence pollinators in their abundance, ecology and behaviour.

Orchids also have specialised interactions with fungal symbionts and this specialisation can also lead to rarity in orchids (Swarts et al., 2010). Most orchids produce miniscule seeds which cannot germinate or survive the seedling stage unless there are specific mycorrhizae present (Warcupp, 1981, Rasmussen \& Rasmussen, 2009). The absence of specific mycorrhizae could therefore also mediate the absence of orchids in suitable grasslands (Otero et al., 2007), and therefore create a colonization credit. However, recent research discovered that many autotrophic terrestrial orchids have a relatively low degree of mycorrhizal specialization (Jacquemyn et al. 2010, Phillips et al., 2011b). Additionally, orchids with a high specificity interacted with common mycorrhiza also available to many other orchid species. Therefore, specialization would not necessarily lead to rarity (Jacquemyn et al., 2010) or a colonization delay. Hence it is unlikely that the mycorrhizal 
distribution is creating an orchid colonization credit in these grasslands.

FUTURE RESEARCH AND MANAGEMENT

Restoration efforts have successfully recreated suitable habitats and numerous calcareous grasslands species have successfully recolonized the area. However, many characteristic species remain rare and are often absent from suitable grasslands. We found some evidence that pollinator specialisation may affect orchid distribution in fragmented calcareous grasslands. Clearly, further research is required, with a focus on pollinator behaviour and abundance in relation to orchids reproductive output, seed dispersal, germination and seedling survival. In addition, management efforts may already focus on the creation of suitable habitats for important pollinators like bumblebees, solitary bees and digger wasps. In the short term, the number of suitable grasslands occupied could also be increased through deliberate sheep migrations between grasslands occupied by orchids and grasslands that are deemed suitable.

\section{Acknowledgements}

This study was funded by the BIOCORE project EV/01/26A, financed by Federal Belgian

Science Policy, and by the research funds of KULeuven (OT/10/034 and OT/08/022/TBA).

PG and DA were funded by FWO. Thanks to L. Woué, L.-M. Delescaille and ir. J-P. Scohy

340 for their kind cooperation. We thank the anonymous reviewers and associated editor $\mathrm{J}$.

341 Kollmann for detailed comments that greatly improved the manuscript. 


\section{Literature Cited}

345

346

347

348

349

350

351

352

353

354

355

356

357

358

359

360

361

362

363

364

365

366

367

368

369

370

Adriaens, D., 2008. Spatio-temporal patterns of calcareous grassland fragmentation and consequences for plant Species and communities, PhD thesis, K.U.Leuven, Leuven, Belgium.

Adriaens, D., O. Honnay and M. Hermy, 2006. No evidence of a plant extinction debt in highly fragmented calcareous grasslands in Belgium. Biological Conservation, 133: 212-224.

Adriaens, D., O. Honnay and M. Hermy, 2007. Does seed retention potential affect the distribution of plant species in highly fragmented calcareous grasslands? Ecography, 30: 505-514.

Arditti, J. and A. K. A. Ghani, 2000. Tansley review No. 110 - Numerical and physical properties of orchid seeds and their biological implications. New Phytologist, 145: 367-421.

Beals, E. W., 1984. Bray-Curtis Ordination: an effective strategy for analysis of multivariate ecological data. Advances in Ecological Research, 14: 1-55.

Bobbink, R. and J. H.Willems, 1987. Increasing dominance of Brachypodium pinnatum (L) Beauv. in chalk grasslands- a threat to a species-rich ecosystem. Biological Conservation; 40: 301-314.

Bowers, M. A., 1986. Density dynamics of bumblebees in subalpine meadows: competition and resource limitation. Holarctic Ecology, 9: 175-184.

Brown, J. H. and A. Kodric-Brown, 1977. Turnover rates in insular biogeography: effect of immigration on extinction. Ecology, 58: 445-449.

Butaye, J., H. Jacquemyn, O. Honnay and M. Hermy, 2002. The species pool applied to forests in a fragmented landscape: dispersal limitation versus habitat limitation. Journal of Vegetation Science, 13: 27-34.

Butaye, J., O. Honnay, D. Adriaens, L-M. Delescaille and M. Hermy, 2005. Phytosociology and phytogeography of the calcareous grasslands on Devonian limestone in Southwest Belgium. Belgian Journal of Botany, 17: 24-38.

Cremene, C., G. Groza, L. Rakosy, A. A. Schileyko, A. Baur, A. Erhardt and B. Baur, 2005. Alterations of steppe-like grasslands in eastern Europe; a threat to regional biodiversity hotspots. Conservation Biology, 19: 1606-1618. 
Cristofoli, S. , J. Piqueray, M. Dufrêne, J. P. Bizoux and G. Mahy, 2010. Colonization credit in restored wet heathlands. Restoration Ecology, 18: 645-655.

Delescaille, L. M., 2005. Calcareous grassland management in Wallonia. Biotechnology, Agronomy, Society and Environment, 9: 119-124.

Eriksson, A. and O. Eriksson, 1997. Seedling recruitment in semi-natural pastures: the effects of disturbance, seed size, phenology and seed bank. Nordic Journal of Botany, 17: 469-482.

Ewald, J., 2002. A probabilistic approach to estimating species pools from large compositional matrices. Journal of Vegetation Science, 13: 191-198.

Hanski, I., 1998. Metapopulation dynamics. Nature, 396: 41-49.

Jackson, S. T. and D. F. Sax, 2010. Balancing biodiversity in a changing environment: extinction debt, immigration credit and species turnover. Trends in Ecology and Evolution, 25: 153-160.

Jacquemyn, H., J. Butaye, and M. Hermy, 2003. Impacts of restored patch density and distance from natural forests on colonization success. Restoration Ecology, 11:417-423.

Jacquemyn, H., K. Vandepitte, I. Roldán-Ruiz, and O. Honnay, 2009. Rapid loss of genetic variation in a founding population of Primula elatior (Primulaceae) after colonization. Annals of Botany, 103: 777-783.

Jacquemyn, H., R. Brys and J. H. Willems, 2005. Does nectar reward affect rarity and extinction probabilities of orchid species? An assessment using historical records from Belgium and the Netherlands. Biological Conservation, 121: 257-263.

Jacquemyn, H., R. Brys, and M. Hermy, 2003. Short-term effects of different management regimes on the response of calcareous grassland vegetation to increased nitrogen. Biological Conservation, 111: 137-147.

Jacquemyn, H., R. Brys, B. Cammue, O. Honnay and B. Lievens, 2010. Low specificity and nested subset structure characterize mycorrhizal associations in five closely-related species of the genus Orchis. Molecular Ecology, 19: 4086-4095.

Jacquemyn, H., C. Van Mechelen, R. Brys and O. Honnay, 2011. Management effects on the vegetation and soil seed bank of calcareous grasslands: results from an 11-year experiment. Biological Conservation, 144: 416-422. 
Kiehl, K., A. Thormann and J. Pfadenhauer, 2006. Evaluation of initial restoration measures during the restoration of calcareous grasslands on former arable fields. Restoration Ecology, 14: 148156.

Kinlan, B. P. and A. Hastings, 2005. Rates of population spread and geographic range expansion. Pages 381-419 in Sax, D.F., J.J. Stachowicz and S.D. Gaines (eds). Species Invasions: Insights into Ecology, Evolution and Biogeography. Sinauer, Sunderland, Massachusetts.

Kuiters, A. T. and H. P. J. Huiskes, 2010. Potential of endozoochorous seed dispersal by sheep in calcareous grasslands: correlations with seed traits. Applied Vegetation Science, 13: 163-172.

Kull, K. and M. Zobel, 1991. High species richness in an Estonian wooded meadow. Journal of Vegetation Science, 2: 715-718.

Kull, T. and M. J. Hutchings, 2006. A comparative analysis of decline in the distribution ranges of orchid species in Estonia and the United Kingdom. Biological Conservation, 129: 31-39.

Lambinon, J., L. Delvosalle L. and J. Duvigneaud, 2004. Nouvelle Flore de la Belgique, du GrandDuché de Luxembourg, du Nord de la France et des Régions voisines. 5th edition. Meise, Jardin botanique national de Belgique.

Lindborg, R. and O. Eriksson, 2004. Historical landscape connectivity affects present plant species diversity. Ecology, 85: 1840-1845.

Menéndez, R., A. G. Megías, J. K. Hill, B. Braschler, S. G. Willis, Y. Collingham, R. Fox, D. B. Roy and C. D. Thomas, 2006. Species richness changes lag behind climate change. Proceedings of the Royal Society B, 273: 1465-1470.

Moilanen, A. and M. Nieminen, 2002. Simple connectivity measures in spatial ecology. Ecology, 83: $1131-1145$.

Münzbergová, Z. and T. Herben, 2004. Identification of suitable unoccupied habitats in metapopulation studies using co-occurrence of species. Oikos, 105: 408-414.

Otero, J. T., N. S. Flanagan, E. A. Herre, J. D. Ackerman and P. Bayman, 2007. Widespread mycorrhizal specificity correlates to mycorrhizal function in the neotropical, epiphytic orchid Ionopsis utricularioides (Orchidaceae). American Journal of Botany, 94: 1944-1950. 
Pärtel, M., A. Helm, T. Reitalu, J. Liira, and M. Zobel, 2007. Grassland diversity related to the Late Iron Age human population density. Journal of Ecology, 95: 574-582.

Pärtel, M., R. Szava-Kovats and M. Zobel, 2011. Dark diversity: shedding light on absent species. Trends in Ecology and Evolution, in press: doi:10.1016/j.tree.2010.12.004.

Perrow, M. R. and A. J. Davy, 2002. Handbook of ecological restoration. Cambridge University Press, Cambridge.

Phillips, R. D., A. P. Brown, K. W. Dixon and S. D. Hopper, 2011a. Orchid biogeography and the factors associated with rarity in a biodiversity hotspot: the Southwest Australian Floristic Region. Journal of Biogeography, 38: 487-501.

Phillips, R. D., M. D. Barrett, K. W. Dixon and S. D. Hopper, 2011b. Do mycorrhizal symbioses cause rarity in orchids? Journal of Ecology, in press: doi:10.1111/j.13652745.2011.01797.x.

Piqueray, J., G. Bottin, L-M. Delescaille, E. Bisteau, G. Colinet and G. Mahy, 2011a. Rapid restoration of a species-rich ecosystem assessed from soil and vegetation indicators: The case of calcareous grasslands restored from forest stands. Ecological Indicators 11: 724-733.

Piqueray, J, S. Cristofoli, E. Bisteau, R. Palm and G. Mahy, 2011b. Testing coexistence of extinction debt and colonization credit in fragmented calcareous grasslands with complex historical dynamics. Landscape Ecology 26: 823-836.

Piqueray, J. and G. Mahy, 2010. Revue bibliographique sur la restauration des pelouses calcicoles en Europe : contraintes rencontrées et solutions proposées. Biotechnologie, Agronomie,Société, Environnement, $14: 471-484$.

Poschlod, P. and M. F. WallisDe Vries, 2002. The historical and socioeconomic perspective of calcareous grasslands - Lessons from the distant and recent past. Biological Conservation, 104: 361-376.

Rasheed, S. A. and L. D. Harder, 1997. Economic motivation for plant species preferences of pollencollecting bumble bees. Ecological Entomology, 22: 209-219.

Rasmussen, H.N. and F. N. Rasmussen, 2009. Orchid mycorrhiza: implications of a mycophagous life style. Oikos, 118: 334-345. 
Samu, F., P. Csontos and C. Szinetár, 2008. From multi-criteria approach to simple protocol: Assessing habitat patches for conservation value using species rarity. Biological Conservation, 141: $1310-1320$.

Schatz, B., 2006, Fine scale distribution of pollinator explains the occurrence of the natural orchid hybrid $\times$ Orchis bergonii. Ecoscience, 13: 111-118.

Shaffer, M. L., 1981. Minimum population sizes for species conservation. BioScience, 31:131-134.

Swarts, N.D. and K.W. Dixon, 2009. Terrestrial orchid conservation in the age of extinction. Annals of Botany, 104: 543-556.

Swarts, N.D., E.A. Sinclair, A. Francis and K.W. Dixon, 2010. Ecological specialization in mycorrhizal symbiosis leads to rarity in an endangered orchid. Molecular Ecology 19: 32263242.

Van Der Cingel, N. A., 1995. An Atlas of Orchid Pollination: European Orchids. A.A. Balkema, Rotterdam,

WallisDeVries, M. F., P. Poschlod and J. H. Willems, 2002. Challenges for the conservation of calcareous grasslands in Northwestern Europe: integrating the requirements of flora and fauna. Biological Conservation, 104: 265-273.

Warcup, J. H., 1981. The mycorrhizal relationships of australian orchids. New Phytologist, 87: 371381.

Waterman, R. J. and M. I. Bidartondo, 2008. Deception above, deception below: linking pollination and mycorrhizal biology of orchids. Journal of Experimental Botany, 59: 1085-1096.

Willis, S. G., J. K. Hill, C. D. Thomas, D. B. Roy, R. Fox, D. S. Blakeley and B. Huntley, 2009. Assisted colonization in a changing climate: a test-study using two U.K. butterflies. Conservation Letters, 2: 45-52.

Young, A., T. Boyle, T. Brown, 1996. The population genetic consequences of habitat fragmentation for plants. Trends in Ecology and Evolution, 11: 413-418. 
480 TABLE I. List of plant traits of all species studied. Traits used: 1) Nectar production (y - yes, n - no), 2)

481 Pollination ( $\mathrm{g}$ - general, s - specialized), 3) Grow habit ( $\mathrm{r}$ - rhizomatous, $\mathrm{t}$ - tuberous), 4) Average plant height at 482 inflorescence $(\mathrm{s}-<30 \mathrm{~cm}, \mathrm{t}-\geq 30 \mathrm{~cm}), 5)$ life-span $(1-$ long-lived (>3 years), s - short-lived $(<3$ years $))$, * 483 unknown, 6) self-compatibility (y - yes, $\mathrm{n}-\mathrm{no})$.

Plant traits

\begin{tabular}{|c|c|c|c|c|c|c|}
\hline Species & 1 & 2 & 3 & 4 & 5 & 6 \\
\hline Epipactis atrorubens & $\mathrm{y}$ & $\mathrm{s}$ & $\mathrm{r}$ & $\mathrm{t}$ & 1 & $\mathrm{n}$ \\
\hline Gymnadenia conopsea & $\mathrm{y}$ & $\mathrm{g}$ & $\mathrm{t}$ & $\mathrm{t}$ & 1 & $\mathrm{y}$ \\
\hline Himantoglossum hircinum & $\mathrm{y}$ & $\mathrm{g}$ & $\mathrm{t}$ & $\mathrm{t}$ & 1 & $\mathrm{y}$ \\
\hline Listera ovata & $\mathrm{y}$ & $\mathrm{g}$ & $\mathrm{r}$ & $\mathrm{t}$ & 1 & $\mathrm{y}$ \\
\hline Ophrys fuciflora & $\mathrm{n}$ & $\mathrm{s}$ & $\mathrm{t}$ & $\mathrm{t}$ & $*$ & $\mathrm{y}$ \\
\hline Ophrys insectifera & $\mathrm{n}$ & $\mathrm{s}$ & $\mathrm{t}$ & $\mathrm{t}$ & $*$ & $\mathrm{y}$ \\
\hline Orchis anthropophora & $\mathrm{y}$ & $\mathrm{s}$ & $\mathrm{t}$ & $\mathrm{t}$ & 1 & $\mathrm{y}$ \\
\hline Orchis mascula & $\mathrm{n}$ & $\mathrm{g}$ & $\mathrm{t}$ & $\mathrm{t}$ & 1 & $\mathrm{y}$ \\
\hline Platanthera chlorantha & $\mathrm{y}$ & $\mathrm{g}$ & $\mathrm{t}$ & $\mathrm{t}$ & 1 & $\mathrm{y}$ \\
\hline
\end{tabular}


485 TABLE II. Principal component analyses with varimax rotation was used to perform a dimension reduction of the 486 measured environmental variables. The component matrix shows the relative values of the environmental 487 conditions, the eigenvalues and percentage of total variance of each principal component.

\begin{tabular}{lccc} 
Variables & PC 1 & PC 2 & PC 3 \\
\hline Rock $(\%)$ & -0.319 & 0.803 & -0.121 \\
Bare ground (\%) & -0.124 & -0.092 & -0.838 \\
Bryophyte $(\%)$ & -0.003 & -0.341 & 0.788 \\
Biomass & 0.889 & -0.315 & 0.080 \\
Vegetation height $(\mathrm{cm})$ & 0.963 & -0.031 & 0.068 \\
Soil dept $(\mathrm{cm})$ & 0.273 & -0.504 & 0.262 \\
Slope $\left({ }^{\circ}\right)$ & 0.042 & 0.850 & 0.034 \\
Eigenvalue & & & 1.15 \\
\% of Variance & 2.76 & 1.27 & 20
\end{tabular}


489 TABLE III. Binary logistic regression equations between grassland suitability and the derived PCs for the orchid 490 species studied.

\begin{tabular}{lcc} 
Species & Regression equation & Model significance \\
\hline$\underline{\text { Epipactis atrorubens }}$ & $-0.410-1.666$ PC2 & $<0.001$ \\
Gymnadenia conopsea & $-0.184-2.483$ PC2 & $<0.001$ \\
$\underline{\text { Himantoglossum hircinum }}$ & & not significant \\
$\underline{\text { Listera ovata }}$ & $-1.632-1.322$ PC2 & $<0.05$ \\
Ophrys fuciflora & & not significant \\
Ophrys insectifera & $-0.712-1.352$ PC2 & $<0.001$ \\
$\underline{\text { Orchis anthropophora }}$ & $-0.738+0.603$ PC2 & $<0.05$ \\
Orchis mascula & & not significant \\
Platanthera chlorantha & $0.862-2.239$ PC2 & $<0.001$
\end{tabular}

491

492 
493 FIGURE 1. Location of the study area in the Viroin valley. Sampled grasslands are indicated in black (Adriaens, 494 Honnay \& Hermy, 2007).

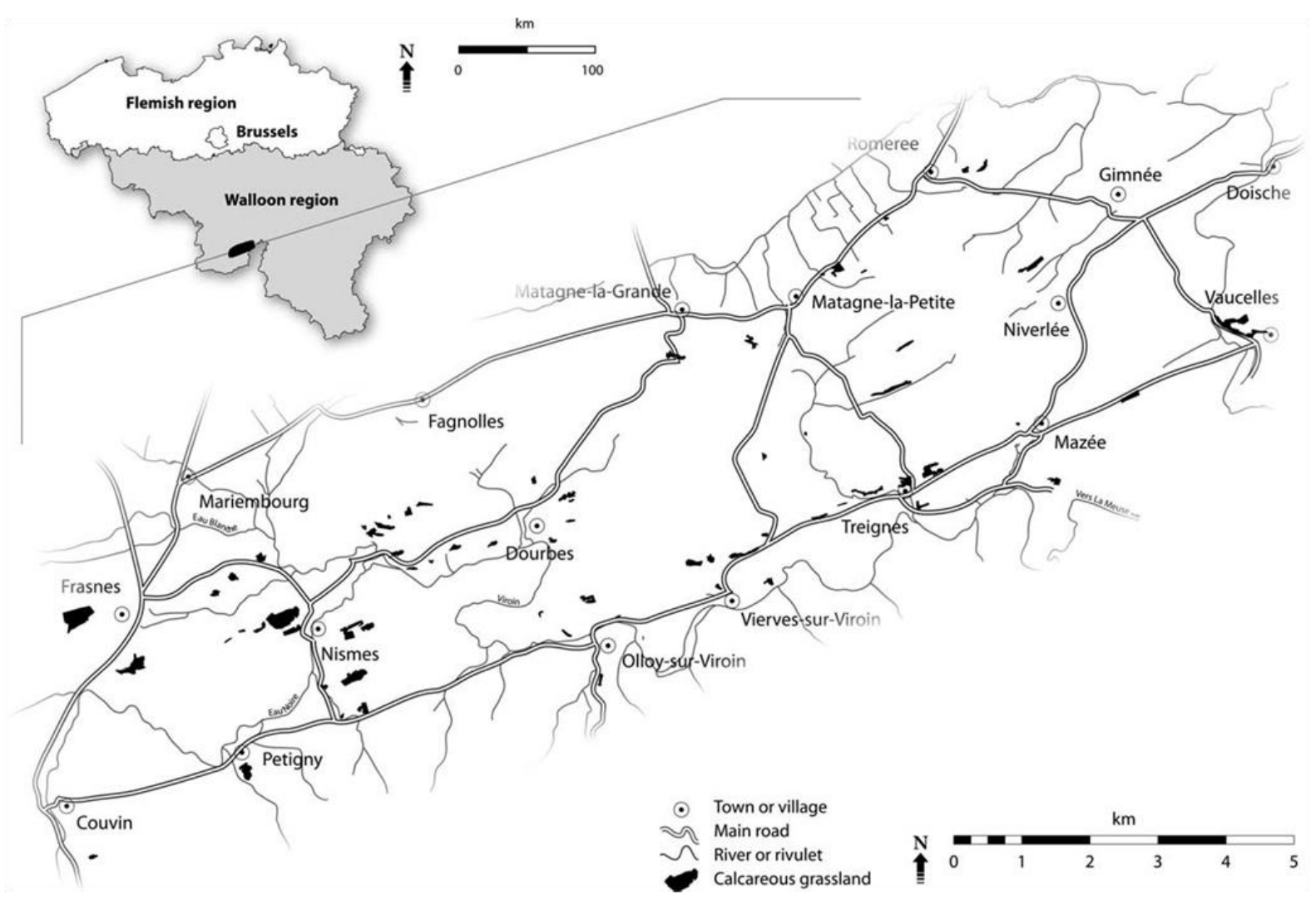

496 
498 FIGURE 2. Beals index values plotted for nine orchid species. Values are separated for occupied (grey) and 499 unoccupied (white) grasslands. Based on the species composition of a grassland the BI predicts habitat 500 suitability. A more suitable grassland has a higher BI. The absolute values of the BI dependent on the frequency 501 of the orchids in the database, hence no between species comparisons can be made.

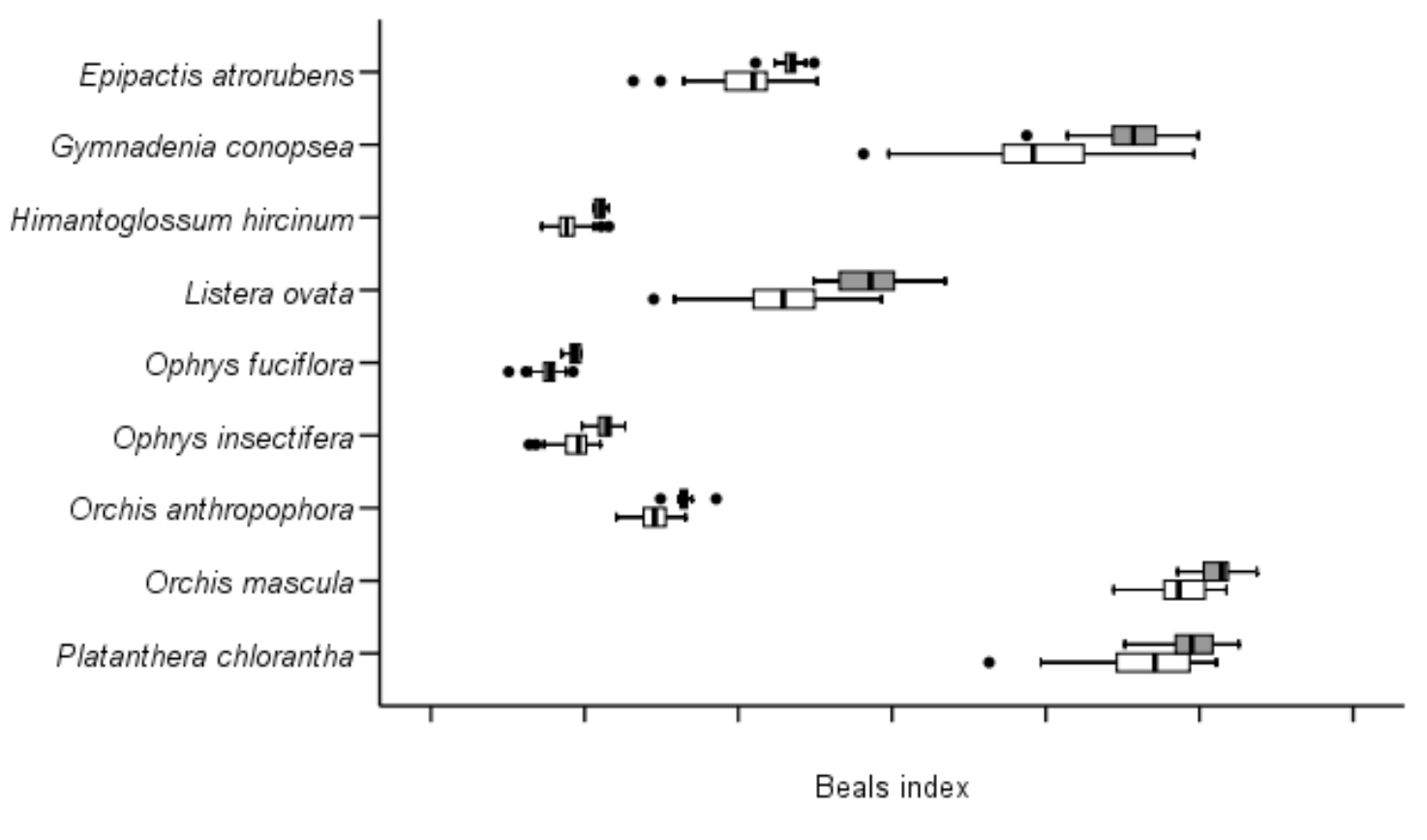


504 FIGURE 3. Absolute number and proportion of suitable grasslands occupied (black) and unoccupied (grey) for the 505 orchid species studied.

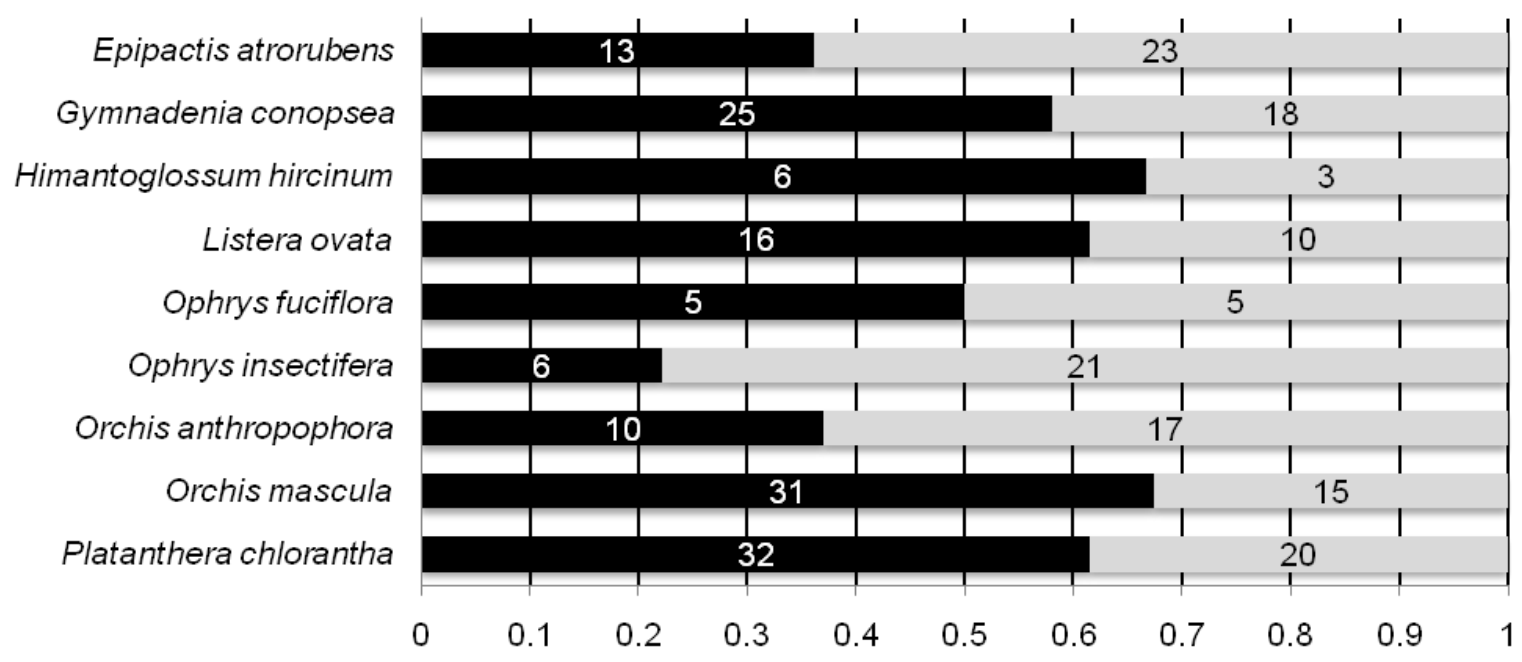

506 
508 FIGURE 4. a) Scatterplot of orchid colonization credit of each grassland vs. log transformation of grassland area.

509 b) Scatterplot of orchid colonization credit of each grassland vs. grassland connectivity. Colonization credit was

510 defined as the number of species yet to colonize a grassland. No significant correlations were found ( $p>0.1$;

511 Spearman rank correlations).

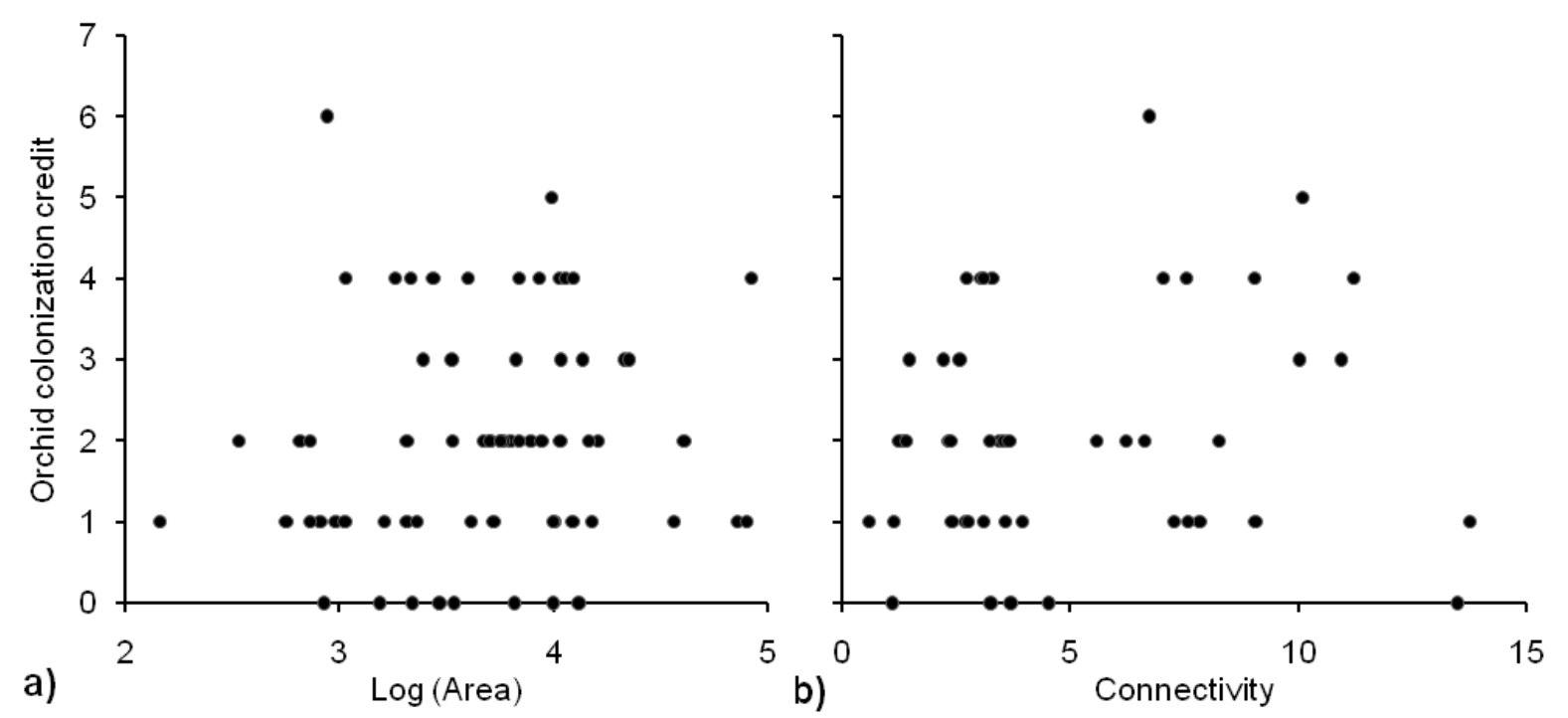

